\title{
José Luis Ramírez Luengo. Léxico histórico del español de Centroamérica. Honduras (1650-1819). Lugo: AXAC, 2018, 341 páginas
}

Virginia Katzen

Katzen, V. (2021). José Luis Ramírez Luengo. Léxico histórico del español de Centroamérica. Honduras (1650-1819). Lugo: AXAC, 2018, 341 páginas. Revista de Filología y Lingüística de la Universidad de Costa Rica, 47(2), e45567. doi: https://doi.org/10.15517/rfl.v47i2.45567

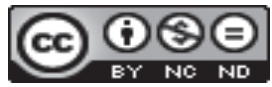

Doi: https://doi.org/10.15517/rfl.v47i2.45567

URL: https://revistas.ucr.ac.cr/index.php/filyling/index 
Revista de Filología y Lingüística de la Universidad de Costa Rica

ISSN: 0377-628X

ISSN: 2215-2628

filyling@gmail.com

Universidad de Costa Rica

Costa Rica

\title{
José Luis Ramírez Luengo. Léxico histórico del español de Centroamérica. Honduras (1650-1819). Lugo: AXAC, 2018, 341 páginas
}

\author{
Katzen, Virginia \\ José Luis Ramírez Luengo. Léxico histórico del español de Centroamérica. Honduras (1650-1819). Lugo: AXAC, \\ 2018, 341 páginas \\ Revista de Filología y Lingüística de la Universidad de Costa Rica, vol. 47, núm. 2, e45567, 2021 \\ Universidad de Costa Rica, Costa Rica \\ Disponible en: http://www.redalyc.org/articulo.oa?id=33266553002 \\ DOI: https://doi.org/10.15517/rfl.v47i2.45567
}

\section{(c) $(1) \Theta$}

Esta obra está bajo una Licencia Creative Commons Atribución-NoComercial-SinDerivar 3.0 Internacional. 
José Luis Ramírez Luengo. Léxico histórico del español de Centroamérica. Honduras (1650-1819). Lugo: AXAC, 2018, 341 páginas

Virginia Katzen

Universidad Nacional de Mar del Plata, Mar del Plata, Argentina

virginia.katzen@mail.ru

(iD https://orcid.org/0000-0003-0634-0615
DOI: https://doi.org/10.15517/rfl.v47i2.45567 Redalyc: http://www.redalyc.org/articulo.oa?id=33266553002

Ramírez Luengo José Luis. Léxico histórico del español de Centroamérica. Honduras (1650-1819). 2018. Lugo. AXAC. 341pp.

A partir de las últimas décadas del siglo XX, pero sobre todo en lo que va del XXI, la lexicografía del español de América cuenta con importantes avances que han sido posibles en gran parte gracias al desarrollo de la lingüística de corpus. Así, han visto la luz obras como Diccionario uruguayo documentado (1966), Diccionario fundamental del español de México (1982), Nuevo Diccionario de Colombianismos (1993), Diccionario de costarriqueñismos (1996), Diccionario del habla de los argentinos y Diccionario de la lengua de la Argentina (2003, 2019), Diccionario del Español de Nicaragua (2007), Diccionario de americanismos (2010), Diccionario de uso del español de Chile (2010), Diccionario del español de México (2010 y 2019) y Diccionario del español del Uruguay (2011), entre otros. También se ha suscitado la discusión de algunos especialistas acerca del alcance de la mayor parte de estas obras. En efecto, frente a una perspectiva contrastiva que hace a los léxicos regionalistas, centrados en la selección diferencial de las entradas respecto de los diccionarios académicos españoles de castellano "general" (como si existiera un único español, trasnacional e indistinto, para cuya descripción se arrogan el derecho exclusivo algunos lexicólogos de España), se contrapone una perspectiva integral hispanoamericana. Esta última considera que una descripción científica de la lengua española de tal o cual zona del mapa americano requiere de una concepción de dicha lengua como sistema, cuya mirada se enfoque en la totalidad lingüística de un momento dado y no en una colección de vocablos que, en cierta manera, complementen los diccionarios "generales". De esta manera Luis Fernando Lara, en su conferencia "El español y sus diccionarios" del 21 de abril de 2020 auspiciada por El Colegio Nacional, señala: "El valor de unidad de la lengua nos llevó a la creencia de que hay un español central, peninsular, rodeado de muchas variedades periféricas. Así se refleja en el ámbito lingüístico la política colonial”. En cuanto a los diccionarios históricos, las cosas no se han desarrollado de la misma manera. Si bien las publicaciones dedicadas a los estudios diacrónicos del español americano ya poseen una gran relevancia (muchísimo menos en América Central, exceptuando el caso de Costa Rica), la realidad es que su plasmación en diccionarios que otorguen organicidad a dichos estudios y que resulten operativos para el investigador ha sido muy escasa. En efecto, las obras de este calibre hasta la actualidad son únicamente el Diccionario histórico del español de Costa Rica (Quesada Pacheco, 1995), el Léxico histórico del español de México: régimen, clases funcionales, usos sintácticos, 
frecuencias y variación gráfica (Company y Melis, 2002) y el Diccionario histórico del español de Venezuela (Pérez, 2013-2016). Por otra parte, la acotación de la mayor parte de estos estudios y aún de los lexicones mencionados (específicamente el costarricense y el venezolano) al aspecto diferencial de las modalidades abordadas del español, resulta en una visión poco objetiva del estado de la lengua como un todo orgánico en los espacios y épocas seleccionados. Esto se debe a que no se estudia el estado de la lengua sino una porción de la misma, cuyo recorte no está establecido con parámetros lingüísticos internos. El problema de base en estas producciones es el ya mencionado a propósito de los diccionarios de español americano: la circunscripción de las variantes de América a dialectos secundarios respecto del español ibérico. La única que supera ampliamente esta problemática, con una propuesta de español integral, es la obra de Company y Melis, cuyo propósito radica precisamente en dar una visión sistémica de la variedad mexicana. Sin embargo, cabe aclarar que este libro no puede ser catalogado como "diccionario": el objetivo de la obra consiste en proporcionar exempla, mas carece de la información de base que debe poseer cualquier obra lexicográfica: las definiciones.

En el contexto mencionado, José Luis Ramírez Luengo edita en 2018 el Léxico histórico del español de Centroamérica. Honduras (1650-1819), resultado del proyecto de investigación "Léxico histórico del español centroamericano (1650-1819)" financiado por la Secretaría de Educación Pública de México. El LHECA Honduras consiste en un repertorio léxico que registra, data y define 1840 voces y 2171 acepciones recuperadas del corpus de documentos históricos Textos para la historia del español XI. Honduras y El Salvador (Ramírez Luengo, 2017). Su forma de presentación es la propia de los diccionarios y posee ejemplos de uso históricos: cada una de las entradas se abre con la etimología de la voz, luego proporciona su caracterización morfológica, en tercer lugar ofrece su/s significado/s junto con la cita de la fuente del/os mismo/s -dando preferencia al Diccionario de la Lengua Española (DLE) de la Real Academia Española (2014), pero también acudiendo a otros diccionarios en unos pocos casos, como el Diccionario de Autoridades, o el Nuevo Diccionario de Americanismos e Indigenismos (NDAI), o bien presentando acepciones propias. Por último, proporciona los ejemplos de uso tomados del corpus histórico de base, citando los documentos correspondientes.

Esta obra de Ramírez Luengo está configurada en función de un interés particularmente lexicológico; así, el autor ha decido incluir las categorías que presentan mayor relevancia para la lexicología: sustantivos, adjetivos, adverbios, verbos, pronombres e interjecciones. Asimismo se incorporaron expresiones pluriverbales más o menos fosilizadas ("de corazón”, “en ayunas", “apagar candelas”, “correr con los gastos”). Se suprimieron sin embargo los vocablos referidos a la onomástica (toponimia y antroponimia) por denotar contenido enciclopédico, así como los elementos que hacen a la sintaxis antes que al estudio del vocabulario, como conjunciones, preposiciones y artículos. La definición de las voces y acepciones se basa mayormente en la establecida por el $D L E$, pero se han incorporado oportunamente aquellas presentes en el corpus que no aparecen en la obra académica (“jolofo/a”, "embudo" y "pasivo” en su acepción sexual). Además, se ha otorgado una entrada independiente a los verbos reflexivos que aparecen en el corpus ("condenarse", "quitarse"), a los participios ("caracterizado/da", "beneficiado"), a las locuciones y expresiones que poseen entrada propia en los diccionarios utilizados como referente ("boca arriba", "dar cordelejo") y a las formas femeninas diferentes de sus correspondientes masculinos ("ella", "doña").

El corpus histórico utilizado (como ya señalamos, editado por el mismo Ramírez Luengo en 2017) consiste en un conjunto de documentos que se aproximan al polo de la inmediatez comunicativa y evidencian características de oralidad transcripta, como denuncias inquisitoriales, declaraciones, testimonios, interrogatorios y otros. La elección de dichos documentos fue llevada a cabo en función de su variedad geográfica dentro del mapa de la República de Honduras y en función de su pertenencia al período tardocolonial, específicamente al segmento cronológico 1650-1819. Esto último responde al hecho de que, para esta época -considerando que el comienzo de la colonización española se desarrolló durante la primera 
mitad del siglo XVI-, el español ya contaba en la región con una profundidad histórica suficiente como para generar una variedad propiamente hondureña del español.

Por todas las características detalladas (la elección y presentación de las voces, el corpus de base y los ejemplos utilizados para su elaboración), el LHECA Honduras se define como un diccionario documentado del español hondureño tardocolonial. El mismo autor lo considera como una primera edición de un trabajo en proceso que se incrementará a medida que se amplíe el corpus de referencia. El léxico ofrecido es de tipo integral; esto significa que no está pensado en función de sus relaciones comunes o diferenciales con el resto del mundo hispánico. Con respecto al concepto de integralidad, Ramírez Luengo señala: “... lo que interesa en un estudio concebido de esta manera no son las unidades peculiares, diferenciales o geográficamente restringidas, sino más bien el conjunto total del vocabulario que [...] forma parte de la variedad seleccionada [...] y obtener, por tanto, una visión más realista del sistema léxico que se utiliza en un momento dado" (Ramírez Luengo 2018, p. 4). Su finalidad consiste, entonces, en proporcionar una visión lo más objetiva posible del sistema lexical propio del ámbito de la inmediatez comunicativa presente en la Honduras de la Colonia. Además, el autor señala que el LHECA Honduras no pretende presentarse como un estudio en sí mismo, sino como una infraestructura operativa para la labor del investigador interesado en estudiar en profundidad el devenir histórico del léxico del español de Centroamérica y de la América hispanófona toda, así como también del español en general. Cabe señalar asimismo la insistencia de Ramírez Luengo en la calidad abierta de la obra, esto es, como un lexicón en proceso, que deja al lector a la espera de ediciones ampliadas para el futuro.

Consideramos que el LHECA Honduras apunta a llenar un gran hueco en la investigación de la historia lingüística de Centroamérica, prácticamente desconocida a excepción de unos meritorios pero escasos estudios (dejando de lado el caso especial de Costa Rica, como ya se ha dicho). Este diccionario es único en su género y presenta un notorio avance en el estudio de la historia del español centroamericano y del español de América, por su carácter de diccionario histórico documentado y su perspectiva integral, aspectos que le otorgan operatividad investigativa y confiabilidad científica. 